\title{
Emergency and elective caesarean sections: comparison of maternal and fetal outcomes in a suburban tertiary care hospital in Puducherry
}

\author{
Valsa Diana $^{1} *$, Arun Tipandjan ${ }^{2}$
}

\author{
${ }^{1}$ Department of OG, Rajeev Gandhi Government Women and Child Hospital, Puducherry, India \\ ${ }^{2}$ Department of Medical Research, Indira Gandhi Government General Hospital and Post Graduate Institute, \\ Puducherry, India
}

Received: 19 January 2016

Accepted: 29 February 2016

\author{
*Correspondence: \\ Dr. Valsa Diana, \\ E-mail: valsadiana@gmail.com
}

Copyright: (c) the author(s), publisher and licensee Medip Academy. This is an open-access article distributed under the terms of the Creative Commons Attribution Non-Commercial License, which permits unrestricted non-commercial use, distribution, and reproduction in any medium, provided the original work is properly cited.

\begin{abstract}
Background: The aim of the current study was to compare the maternal and fetal outcomes of emergency and elective caesarean deliveries.

Methods: A prospective case comparative study was conducted at the Government Maternity Hospital, Department of Obstetrics and Gynaecology, Puducherry, from August 2005 to July 2006.

Results: A total of 301 caesarean deliveries occurred during the study period. The percentages of the primi-gravida as well as the nulli-parous women were significantly higher among emergency caesarean section than that in elective caesarean section $\left(\chi^{2}=12.52, \mathrm{P}<0.0001\right)$. The percentages of previous caesarean sections was significantly higher among those who had elective caesarean than those had emergency caesarean section in the present delivery $\left(\chi^{2}=14.73, \mathrm{P}=0.0001\right)$. Among emergency caesarean section $25.8 \%$ had abdominal distension, whereas it was present only in $8.7 \%$ of the elective cases. Of the 16 new born with postnatal complications in the emergency group, 14 died, one had convulsion and the remaining one was a stillbirth. In the elective group there were 4 deaths.

Conclusions: It was inferred that both elective and emergency caesarean imposes certain complications to the mother and the fetes. However, maternal and fetal complications were felt very high in emergency caesarean than elective. Proper planning can help obstetric practitioners to avoid complications.
\end{abstract}

Keywords: Caesarean section, Elective, Emergency, Complications

\section{INTRODUCTION}

Caesarean section (CS) is the termination of pregnancy and delivery of the live or dead foetus through an incision on the abdominal and uterine wall. Surgical interventions during pregnancy are performed to improve the parturition outcome. But the procedure by itself carries inherent risks. In a large study of 33 teaching hospitals in 1993 in India, caesarean rates varied from $8 \%$ to $36 \% .^{1}$ In 1985 the World Health Organization stated: There is no justification for any region to have caesarean section rates higher than $10-15 \% .^{2}$
The incidence of CS varies between 10 and $25 \%$ in most developed countries. ${ }^{3}$ In many countries the frequency of caesarean section is on the rise. ${ }^{4}$ The increased rate of caesarean section in the present scenario is due to increase in maternal age. ${ }^{5}$ Maternal mortality and morbidity are on the rise following CS when compared to vaginal delivery. ${ }^{6}$ Emergency caesarean sections are commonly performed for fetal distress, prolonged obstructed labour, and severe pre eclampsia and ruptured uterus. The current study aims at establishing a comparison of the maternal and fetal outcomes between 
elective CS and emergency CS in a tertiary care hospital in Puducherry.

\section{METHODS}

A prospective case comparative study was conducted at the Government Maternity Hospital, Department of Obstetrics and Gynaecology, Puducherry, from August 2005 to July 2006. 150 elective and 151 emergency caesarean cases where compared during this period.

Prior to initiation of the study a sample size and power analysis was carried out by utilizing available data on incidence of post-operative fever morbidity in elective and emergency caesarean sections in India. Accordingly a sample of at least 86 women was required in each group to show a difference of $20 \%$ in febrile morbidity between elective and emergency caesarean sections to achieve a statistical power of $80 \%$ and confidence level of $95 \%$. Considering the minimum sample size required for each group, it was decided to recruit a total of 300 women for this prospective study.

Pre-term deliveries were excluded from the study. Information regarding socio demographic variables such as age, parity, weight, socio-economic status and literacy were collected. Complete obstetric examination was done and the details of antenatal complication such as gestational diabetes mellitus, pregnancy induced hypertension, anaemia, heart disease, seizure disorder, HIV, syphilis, HBsAg were obtained. Indication for caesarean section and data regarding intra operative findings, post-operative complications were gathered. Neonatal data such as birth weight, APGAR score, admission to neonatal ICU were included. Primary outcome measures collected were incidence of UTI, febrile morbidity, abdominal distension, respiratory infection and wound infection in addition to postoperative measures required for morbidity management. The measures of morbidity management include blood transfusion and antibiotics. Also data on days of oral route, ambulation, and suture removal, duration of hospital stay and post-natal morbidity status of mother and child were recorded.

\section{Statistical analysis}

Student's t-test for independent samples was used for analysis of continuous variables. Heterogeneity chisquare test or Fisher's exact test (if numbers were small) was used to compare categorical variables. $P$ value of $<0.05$ was considered as statistically significant. Binary logistic regression was used to evaluate the odds ratio. All the analyses were carried out using SPSS version 18.0.

\section{RESULTS}

Majority of the elective caesareans (83\%) were done for cases which were booked in the maternity hospital, whereas emergency caesarean of booked cases constituted only $53 \%$ and the remaining were either booked outside $(40 \%)$ or un-booked $(7 \%)$. The association of type of case and the type of caesarean was found to be highly significant $\left(\chi^{2}=33.9, \mathrm{P}<0.0001\right)$.

Table 1: Indications of caesarean section.

\begin{tabular}{|llllll|}
\hline Indications for caesarean Section & Elective caesarean & $\%$ & Emergency caesarean $^{\text {\% }}$ & P value $^{\#}$ \\
\hline Previous caesarean section with CPD & 115 & 76.7 & 51 & 33.8 & $0.00^{*}$ \\
\hline Fetal Distress & 13 & 8.7 & 35 & 23.8 & $0.00^{*}$ \\
\hline Malpresentations & 6 & 4.0 & 14 & 9.3 & 0.07 \\
\hline Failed induction & 1 & 0.7 & 9 & 6.0 & $0.02^{*}$ \\
\hline Dystocia & 14 & 9.3 & 23 & 15.2 & 0.12 \\
\hline APH & 0 & 0.0 & 9 & 6.0 & - \\
\hline BOH & 1 & 0.7 & 0 & 0.0 & - \\
\hline Others & 0 & 0.0 & 9 & 6.0 & - \\
\hline Total & 150 & 100.0 & 150 & 100.0 & - \\
\hline
\end{tabular}

The urban and rural populations for elective caesarean were $74 \%$ and $26 \%$ and for emergency caesarean section $54 \%$ and $46 \%$ respectively. These figures suggest that relatively small percentage of the women from rural area elected to undergo caesarean sections compared to those in urban area.
Women from the medium and high socio-economic status constitute $62 \%$ of the elective caesarean cases compared to $26 \%$ of the same category from the emergency caesarean section. While only $38 \%$ of the women from low socio-economic status opted for elective caesarean, $74 \%$ had undergone emergency caesarean sections. The percentage distributions of women by socio-economic status $\left(\chi^{2}=40.7, \mathrm{P}<0.001\right)$ and rural/urban classifications 
$\left(\chi^{2}=10.0, \mathrm{P}=0.002\right)$ differ significantly between elective and emergency caesarean sections.

The age-distribution showed that $85 \%$ and $91 \%$ of the women were in the age-group of 18-30 years and $15 \%$ and $9 \%$ were in 31-40 years in the elective and emergency caesarean sections respectively. The percentages of women in the two groups do not differ significantly $\left(\chi^{2}=2.69, \mathrm{P}=0.10\right)$.
The percentages of the primi-gravida as well as the nulliparous women were significantly higher among emergency caesarean section than that in elective caesarean section $\left(\chi^{2}=12.52, \quad \mathrm{P}<0.0001\right)$. The mean weight of women in elective caesarean section was significantly higher than that of the women in emergency caesarean section (Student's t-test for independent sample, $\mathrm{t}=5.6, \mathrm{P}<0.0001)$. The percentage of previous history of abortions was significantly higher among elective caesarean group than that in emergency caesarean group $\left(\chi^{2}=8.2, \mathrm{P}=0.004\right)$.

Table 2: Post-operative complications of elective and emergency caesarean section.

\begin{tabular}{|c|c|c|c|c|c|c|}
\hline Post-operative complications & Elective & $\%$ & Emergency & $\%$ & OR $(95 \% \mathrm{CI})$ & P value ${ }^{\#}$ \\
\hline UTI & 19 & 12.7 & 26 & 17.2 & $1.4(0.7-2.9)$ & 0.26 \\
\hline Abdominal distension & 13 & 8.7 & 39 & 25.8 & $3.7(1.8-7.6)$ & $<0.001^{*}$ \\
\hline Respiratory infection & 8 & 5.3 & 22 & 14.6 & $3.0(1.2-7.7)$ & $0.007^{*}$ \\
\hline Wound infection & 3 & 2.0 & 5 & 3.3 & $1.7(0.3-10.9)$ & 0.72 \\
\hline Burst abdomen & 6 & 4.0 & 5 & 3.3 & $0.8(0.2-3.1)$ & 0.75 \\
\hline Pelvic masses & 3 & 2.0 & 4 & 2.6 & $1.3(0.2-9.3)$ & 0.99 \\
\hline Thrombophelbits & 8 & 5.3 & 17 & 11.3 & $2.3(0.9-5.9)$ & 0.06 \\
\hline Fever & 2 & 1.3 & 5 & 3.3 & $2.5(0.4-26.9)$ & 0.45 \\
\hline Wound dehiscence & 0 & 0.0 & 1 & 0.7 & - & - \\
\hline Retained placenta & 0 & 0.0 & 3 & 2.0 & - & - \\
\hline No complications & 114 & 76.0 & 77 & 51.0 & $0.3(0.2-0.55)$ & $<0.001^{*}$ \\
\hline
\end{tabular}

"Heterogeneity chi-square or Fisher's exact test. Indicates difference is significant at $\mathrm{P}<0.05$. Indicates statistical test cannot be done due to small numbers in some cells.

Table 3: Distribution of APGAR score for babies born to elective and emergency caesarean cases.

\begin{tabular}{|lllllll|}
\hline APGAR score & Elective & $\%$ & Emergency & $\%$ & OR (95\% CI) & P-value $^{\#}$ \\
\hline Above 8 & 139 & 92.7 & 110 & 72.8 & $0.2(0.1-0.5)$ & $<0.0001^{*}$ \\
\hline $7-8$ & 10 & 6.7 & 35 & 23.2 & $3.9(1.8-8.8)$ & $0.0002^{*}$ \\
\hline Below 6 & 1 & 0.7 & 6 & 4.0 & $6.2(0.7-285.5)$ & 0.12 \\
\hline Total & 150 & 100.0 & 151 & 100.0 & - & - \\
\hline
\end{tabular}

Table 4: Comparison of postnatal complications in mothers of the elective and emergency caesarean cases.

\begin{tabular}{|lll|}
\hline Post-natal follow up of mothers & Elective & Emergency \\
\hline With complication & 5 & 9 \\
\hline Bladder injury & 1 & 0 \\
\hline BLYNCH & 0 & 1 \\
\hline Burst abdomen & 0 & 1 \\
\hline Classical LSCS & 1 & 0 \\
\hline Hernia repair & 2 & 1 \\
\hline Hysterectomy & 0 & 2 \\
\hline Ovarian cystectomy & 0 & 1 \\
\hline Rupture uterus & 0 & 1 \\
\hline wound infection & 1 & 2 \\
\hline Without complication & 79 & 46 \\
\hline Total & 84 & 55 \\
\hline
\end{tabular}


The percentages of previous caesarean sections was significantly higher among those who had elective caesarean than those had emergency caesarean section in the present delivery $\left(\chi^{2}=14.73, \mathrm{P}=0.0001\right)$. Thus the results suggest that the decision to have elective caesarean in the present study mainly depends on women who had one or more previous caesarean sections prior to the present delivery.

When comparing the medical complications in elective and emergency caesarean groups, the incidence of anaemia was about 3 times higher in emergency caesarean $(19.9 \%)$ cases compared to emergence cases (8.0\%) $(\mathrm{OR}=2.9, \mathrm{P}<0.05)$. PIH was similar both in emergency $(9.9 \%)$ and in elective $(8.7 \%)$ caesarean cases. The difference was not statistically significant $(\mathrm{OR}=1.2$, $\mathrm{P}>0.05)$.

Of the 150 elective cases $16(10.7 \%)$ had one or more complications in elective group. In contrast out of 151 emergency $78(51.7 \%)$ had intrapartum complications. Those who had undergone emergency caesarean had 9 times more risk of having intrapartum complications than those who opted for elective caesarean $(\mathrm{OR}=9.0, \mathrm{P}<0.05)$. A large proportion of the emergency cases were having premature rupture of membrane (PROM, 33.1\%) compared to $5.3 \%$ among elective cases. Meconium stained labour, prolonged labour and APH were the other complications which persisted in $6.6 \%, 5.3 \%$ and $4.0 \%$ of the emergency cases and $4.0 \%, 0.7 \%$ and $0.0 \%$ of the elective cases respectively. Emergency cases had significantly higher incidences of PROM and prolonged labour compared to elective cases $(\mathrm{P}<0.05)$ for both comparisons. All other intrapartum complications have occurred only in small proportions of the cases but they do not differ significantly between the groups $(\mathrm{P}>0.05)$.

Table 5: Postnatal complication in new borns.

\begin{tabular}{|c|c|c|c|c|}
\hline $\begin{array}{l}\text { Postnatal } \\
\text { complications } \\
\text { in new borns }\end{array}$ & $\begin{array}{l}\text { Elective } \\
(\%)\end{array}$ & $\begin{array}{l}\text { Emergency } \\
(\%)\end{array}$ & $\chi^{2 \#}$ & $\begin{array}{l}\text { P- } \\
\text { value }\end{array}$ \\
\hline $\begin{array}{l}\text { With } \\
\text { complication }\end{array}$ & $4(2.7)$ & $16(10.6)$ & 7.6 & 0.006 \\
\hline Convulsions & $0(0.0)$ & $1(0.7)$ & - & - \\
\hline Expired & $4(2.7)$ & $14(9.3)$ & 5.8 & 0.015 \\
\hline Stillbirth & $0(0.0)$ & $1(0.7)$ & - & - \\
\hline
\end{tabular}

Previous caesarean section with CPD was the major indication for caesarean section in either group. While only in $33.8 \%$ of the emergency cases had previous caesarean section as indication for present caesarean, $76.7 \%$ of the elective cases had this indication. The second commonest indication was dystotica in the elective group, which was indicated in $9.3 \%$ of the elective cases and $15.2 \%$ in emergency cases. In the emergency group, the $1^{\circ} \mathrm{CPD}$ failed trial was the second commonest indication (23.8\%), which was $8.7 \%$ in elective cases. Malpresenation was found in $9.3 \%$ and
$4.0 \%$ of the emergency and elective caesareans cases respectively. In emergency cases $6.0 \%$ had failed induction and another $6.0 \%$ had APH as indications for caesarean sections.

The overall incidences of complications was significantly higher in emergency caesarean section $(28.5 \%)$ than that in elective section $(16.7 \%)(\mathrm{P}<0.05)$. Atonic post-partum haemorrhage was the major intra-partum complication in both elective $(6.7 \%)$ and emergency $(17.9 \%)$ caesarean sections. The odds of occurrence of this complication was 3 times higher in emergency cases than that in elective group $(\mathrm{P}<0.05)$. All other complications were present in either group $(\mathrm{P}>0.05)$.

Among emergency caesarean section $25.8 \%$ had abdominal distension, whereas it was present only in $8.7 \%$ of the elective cases. The difference was statistically significant $(\mathrm{OR}=3.7, \quad \mathrm{P}<0.001)$. Lower respiratory tract infection (LRT) was significantly higher in emergency cases $(13.2 \%)$ than that in emergency cases $(4.7 \%)$. The odds of this presentation were 3.1 (OR) times higher in emergency cases than that in elective cases $(\mathrm{P}<0.05)$. All other complications were equally present in both the groups (Table 2).

APGAR score of Above 8 was noticed in $92.7 \%$ of the babies born to elective cases and $72.8 \%$ of the babies born to emergency cases (Table 3 ). Thus a significantly higher proportion of the babies born to elective caesarean cases had good APGAR score compared to those born to emergency cases $(\mathrm{P}<0.05)$. Further $23.2 \%$ of the babies in emergency cases had an APGAR score of 7-8 when compared to $6.7 \%$ in the elective group and significant difference was found $(\mathrm{P}<0.05)$. The APGAR score was below 6 for $4 \%$ of the babies born to emergency caesarean cases and $0.7 \%$ of the elective cases. The difference was not significant between groups (Heterogeneity chi-square test, $\mathrm{P}=0.12$ ).

Table 4 shows the distribution of elective and emergency cases by postnatal complications. Of the 150 mothers in the elective group 84 (56\%) turned up for follow up, whereas in emergency group only $55(36.4 \%)$ out of 151 turned up. Thus the drop outs were more in the emergency group (44\%) compared to $63.6 \%$ in the emergency group. Overall incidence of postnatal complications was 5 and 9 in elective and emergency caesarean cases respectively. However the difference in incidence between the two groups was at the limits of statistical significance (Heterogeneity chi-square test, $\chi^{2}$ $=3.98, \mathrm{P}=0.046$ ).

The overall incidence of complications in new borns was 4 and 16 in the elective and emergency caesarean sections respectively (Table 5). The incidence rate was significantly higher in the emergency cases $(10.6 \%)$ compared to elective cases $(2.7 \%)$ (Heterogeneity chisquare test, $\left.\chi^{2}=7.6, \mathrm{P}=0.006\right)$. Of the 16 new borns with postnatal complications in the emergency group, 14 died, 
one had convulsion and the remaining one was a stillbirth. In the elective group there were 4 deaths. The incidence of infant mortality was significantly higher among emergency cases $(9.3 \%)$ than that in elective cases $(2.7 \%)$ (Heterogeneity chi-square test, $\left.\chi^{2}=5.8, P=0.015\right)$.

\section{DISCUSSION}

The aim of this study is to find out the maternal and fetal outcomes of elective and emergency caesarean section. Elective CS was more common among the urban women whereas emergency caesarean section were more common among rural women. This may be due to better facilities and patient-care available to the urban population when compared to the rural population. Women who were booked during their antenatal period in the hospital were observed to have a lower chance of emergency CS when compared to the women who were unbooked or booked outside.

Adashek et al in their study observed a higher mean maternal age among women who underwent caesarean section when compared to vaginal delivery. ${ }^{5}$ In the current study we had observed a higher mean maternal age among elective caesarean compared to emergency caesarean cases. Also a higher maternal weight was observed in elective CS group.

Previous caesarean remained at the top of the list of indications for both elective and emergency CS. Fetal distress is a leading indication among emergency CS. This is in accordance to previous study conducted by Rehana et al where they observed repeat caesarean section in $22.5 \%$ of multigravity undergoing $\mathrm{CS}^{7}$. Sowmya et al had established that caesarean delivery is the commonest cause in elective group. ${ }^{8}$

Although usually lifesaving, caesarean delivery increases maternal and new born risks and this happens more commonly in emergency CS., , $^{-12}$

Maternal intra-operative and post-operative complications were more common in the emergency cases as compared to elective ones. In study by Rehana et al overall intra operative complications were $11.88 \%$ which was mainly contributed by the emergency group. ${ }^{7}$

Burrows and associates reported maternal morbidity increased dramatically with Caesarean Section compared with vaginal delivery he concluded that the principal sources are puerperal infection, hemorrhage and thrombo - embolism. ${ }^{13}$ In our study we found urinary tract infection to be the most common cause of post caesarean complication that was alike the findings in the study conducted by Leigh et al. ${ }^{14}$

Low APGAR score and asphyxia is a much bigger problem in emergency $\mathrm{CS}^{8}{ }^{8}$
Birth asphyxia was seen in $2.1 \%$ newborns after Emergency Caesarean Section whereas it was $1.3 \%$ after Elective Caesarean Section and the difference was not statistically significant. ${ }^{15}$

\section{CONCLUSION}

It was inferred that both elective and emergency caesarean impose certain complications to the mother and the fetes. However, maternal and fetal complications were felt very high in emergency caesarean than elective. Proper planning can help obstetric practitioners to avoid complications.

\section{Funding: No funding sources \\ Conflict of interest: None declared \\ Ethical approval: The study was approved by the ethical committee of IGGGH and PGI, Puducherry}

\section{REFERENCES}

1. Rao BK. Global aspects of a rising caesarean section rate. In Women's health today: perspectives on current research and clinical practice. The proceedings of the XIV world congress of obstetrics and gynecology, Montreal 1994:59-64.

2. World Health Organization. Appropriate technology for birth. Lancet. 1985;2:436-7.

3. Dewhurst's Textbook of Obstetrics and Gynaecology for post graduates Seventh edition. Edited by D. Keith Edmonds. Malpresentation, Malposition, cephalopelvic disproportion and obstetric procedures. Blackwell publishing. London. 2007:223-4.

4. Landon MB, Hauth JC, Lenevo KL, Spong CY. Maternal and perinatal outcome associated with a trial of labor after prior caesarean delivery. N England J Med. 2005;352:1718-20.

5. Landon MB, Hauth JC, Leveno KJ, Spong CY, Leindecker S, Varner MW, et al. Maternal and perinatal outcomes associated with a trial of labor after prior cesarean delivery. Obstetrical and gynecological survey. 2005;60:291-3.

6. Adashek JA, Peaceman AM, Lopez-Zeno JA, Minogue JP, Socol ML. Factors contributing to the increased cesarean birth rate in older parturient women. American journal of obstetrics and gynecology. 1993;169:936-40.

7. Blackwell publishing. London 2007. Hall MH. Variation in caesarean section rate: maternal mortality higher after c-section. British Medical Journal. 1994;308:654-55.

8. Hall MH. Variation in caesarean section rate. Maternal mortality higher after caesarean section. BMJ: British Medical Journal. 1994;308:654. Rehana N , Reena S. Maternal and fetal outcomes in elective and emergency caesarean sections at a teaching hospital in north India. A retrospective study. Journal of Advance Researches in Biological Sciences. 2013;5:5-9. 
9. Sowmya M, Dutta I. Comparative Study of Neonatal outcome in Ceasarean section done in referred cases vs Elective Ceasarean delivery in a rural medical college hospital. Journal of Evolution of Medical and Dental Sciences. 2014; 24:13993-8.

10. Villar J, Valladares E, Wojdyla D, Zavaleta N, Carroli G, Velazco A, et al. Caesarean delivery rates and pregnancy outcomes: the 2005 WHO global survey on maternal and perinatal health in Latin America. Lancet. 2006;367:1819-29.

11. Hasssan S, Tariq S, Javaid MK. Comparative analysis of problems encountered between patients of elective caesarean section and patient for whom elective caesarean section was planned but ended up in emergency. Professional Med J. 2008;15:211-5.

12. Hassan S, Tariq S, Javaid MK. Emergency caesarean section; Comparative analysis of problems encountered between patients of elective caesarean section and patient for whom elective caesarean section was planned but ended up in emergency. Prof Med J. 2008;15:211-5.

13. Promila J, Harneet K, Vidushi B, Annika J A. Comparison of Maternal and Fetal Outcome in Elective and Emergency Caesarean FCS 8 Sections. Indian Obstetrics and Gynaecology. 2012 ;2(3).
14. Factors affecting the rate and Indications of primary CS FCS 9. Available at: http://www.bahrainmedicalbulletin.com/december_2 001/factors.pdf.

15. Burrows LJ, Meyn LA, Weber AM. Maternal morbidity associated with vaginal versus cesarean delivery. Obstetrics and Gynecology. 2004;103:90712.

16. Leigh DA, Emmanuel FX, Sedgwick J, Dean R. Post-operative urinary tract infection and wound infection in women undergoing caesarean section: a comparison of two study periods in 1985 and 1987. Journal of Hospital infection. 1990;15(2):107-16.

17. Daniel S, Viswanathan M, Simi, Nazeema. Comparison of Fetal Outcomes of Emergency and Elective Caesarean Sections in a Teaching Hospital in Kerala. Academic medical journal of India. 2014;23.

18. Daniel S, Viswanathan M, Simi BN, Nazeema A. Comparison of Fetal Outcomes of Emergency and Elective Caesarean Sections in a Teaching Hospital in Kerala. Academic Medical Journal of India. 2014;2:32-6.

Cite this article as: Diana V, Tipandjan A. Emergency and elective caesarean sections: comparison of maternal and fetal outcomes in a suburban tertiary care hospital in Puducherry. Int $\mathbf{J}$ Reprod Contracept Obstet Gynecol 2016;5:3060-5. 